\title{
Promoção da saúde física e mental e de bem estar no ambiente universitário
}

\author{
Maria Lucia do Carmo Cruz Robazzi ${ }^{1}$
}

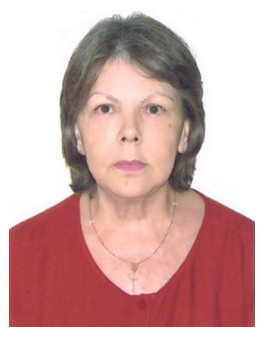

Local em que acontece o ensino de nível superior e os conhecimentos são gerados e onde se procura analisar e atender aos desafios ocorridos na sociedade, a Universidade é um espaço privilegiado para se conhecer a cultura universal e as várias ciências, para criar e divulgar o saber, possuindo o papel de fortalecer a cidadania e desenvolver a inquietude do ser social(1-2).

Entretanto, nesse mesmo ambiente exige-se muita produtividade, tanto dos alunos quanto dos trabalhadores docentes e não docentes. Há a cobrança por numerosas pesquisas que exigem financiamentos; há a exigência de papers publicados em periódicos nacionais e internacionais com boas qualificações; ocorre a necessidade de inovar-se o ensino, objetivando que os temas tratados nas disciplinas motivem o aprendizado dos alunos; existe a indicação para que as disciplinas sejam ofertadas em outros idiomas no intuito de atrair universitários de diversos países; há a necessidade de obtenção de recursos financeiros, para o desenvolvimento dos variados projetos, entre outros. No meio de todo esse universo existe, também, no âmbito das universidades públicas, a questão do contingenciamento dos recursos financeiros, o que vem dificultando a realização de atividades de ensino e pesquisa. Acresce-se, ainda, que os gestores universitários acompanham, com interesse, as determinações das exatas posições das universidades em relação às dos outros países, as quais acontecem periodicamente, exigindo do seu pessoal melhoras nas performances nestes ranqueamentos.

Esse ambiente, que acaba sendo muito competitivo, afeta a saúde da tríade constituída por professores, funcionários técnicos-administrativos e alunos, de graduação e de pós-graduação.

${ }^{1}$ Universidade de São Paulo, Escola de Enfermagem de Ribeirão Preto, Centro Colaborador da OPAS/OMS para o Desenvolvimento da Pesquisa em Enfermagem, Ribeirão Preto, SP, Brasil.

\section{Como citar este artigo}

Robazzi MLCC. Promotion of physical and mental health and well-being in the university environment. SMAD, Rev Eletrônica Saúde Mental Álcool Drog. 2019;15(2):1-3. doi: https://dx.doi.org/10.11606/issn.1806-6976.smad.2019.154951. 
A partir disso, são observadas alterações à saúde física e mental, hábitos indesejáveis e convivência com agentes variados de riscos entre essas pessoas. Entre esses problemas encontram-se as alterações vocais ${ }^{(3)}$, o estresse e os sintomas osteo-musculares ${ }^{(4)}$, a inatividade física que pode se associar ao risco para Doenças Crônicas Não Transmissíveis(5), o uso de álcool e/ou outras drogas( ${ }^{(6-7)}$, a síndrome do esgotamento profissional(8-9), entre outros.

Nesse sentido torna-se necessário buscar, nas Universidades, um ambiente mais saudável, com a presença de bem-estar, para que as pessoas que nele estão não adoeçam.

A Escola de Enfermagem de Ribeirão Preto-USP coordenou um estudo sobre o Bem-Estar em Universidades, que aconteceu, simultaneamente, com outras cinco escolas de enfermagem brasileiras, de Universidades estaduais e federais, das regiões Nordeste, Sul, Centro-Oeste e Sudeste. O projeto envolveu uma equipe constituída por enfermeiros, fisioterapeutas, nutricionistas, educadores físicos, contando com a colaboração de graduandos e de pósgraduandos. Durante um período de três meses, em todos os locais, foram realizadas atividades de caminhadas (três vezes na semana), orientações nutricionais (uma vez na semana), verificação dos parâmetros vitais, com ênfase na Pressão Arterial (antes do início das atividades e após o seu encerramento), verificação dos níveis de bem-estar, atividades de isostretching (duas vezes na semana), entre outras. Considerando-se que nem todas as escolas de enfermagem possuíam atividades de pós-graduação, o estudo foi direcionado aos graduandos de enfermagem e aos trabalhadores docentes e não docentes dessas universidades.

Os resultados mostraram que as intervenções propostas foram eficazes para melhorar a qualidade de vida dos docentes, não docentes e dos alunos das universidades investigadas. Além disso, proporcionaram melhor entendimento sobre a situação de saúde, com a monitoração de sinais vitais, da fadiga, do bem estar, de dores osteomusculares, entre outros. Na avaliação da alteração da saúde dos participantes, notou-se que os sintomas foram reduzidos após as intervenções ${ }^{(10)}$.

Desta forma, considerou-se que os participantes passaram a ter melhor percepção dos sintomas, conseguindo eliminá-los com atividades regulares e adaptação alimentar. Na avaliação do bem estar, particularmente entre os graduandos, percebeu-se que os valores finais foram aumentados em relação aos iniciais, evidenciando-se que as intervenções foram satisfatórias para os alunos. Entretanto, parte da população não conseguiu atingir níveis satisfatórios de diminuição da fadiga e de $\operatorname{dores}^{(10)}$.

Esses resultados mostraram que há a necessidade de mais investimentos em pesquisas voltadas para a saúde dos alunos e trabalhadores docentes e não docentes das universidades brasileiras, objetivando o seu não adoecimento físico e mental, promovendo ações para a melhoria das condições de vida, de trabalho e de estudo desta população.

\section{Referencias}

1. Marcovitch J. A universidade (im)possível. São Paulo: Futura, 1998.

2. Wanderley LEW. O que é universidade? 9 ed. São Paulo: Editora Brasiliense. Coleção Primeiros Passos, 1988.

3. Alves Liliana Amorim, Robazzi Maria Lúcia do Carmo Cruz, Marziale Maria Helena Palucci, Felippe Ana Clara Naufel de, Romano Cristiane da Conceição. Alterações da saúde e a voz do professor, uma questão de saúde do trabalhador. Rev. Latino-Am. Enfermagem [Internet]. 2009 Ago [citado 2018 Nov 05]; 17 (4): 566-572. Disponível em: http:// www.scielo.br/scielo.php?script=sci_arttext\&pid=S0104-11692009000400020\&lng=pt. http://dx.doi.org/10.1590/ S0104-11692009000400020.

4. Almeida Letícia Maria da Silva, Dumith Samuel de Carvalho. Associação entre sintomas osteomusculares e estresse percebido em servidores públicos de uma Universidade Federal do Sul do Brasil. BrJP [Internet]. 2018 Mar [cited 2018 Nov 05]; 1 (1): 9-14. Available from: http://www.scielo.br/scielo.php?script=sci_arttext\&pid=S259531922018000100009\&Ing=en. http://dx.doi.org/10.5935/2595-0118.20180004

5. Santana Jaqueline de Oliveira, Peixoto Sérgio Viana. Inatividade física e comportamentos adversos para a saúde entre professores universitários. Rev Bras Med Esporte [Internet]. 2017 Apr [cited 2018 Nov 05]; 23 (2): 103108. Available from: http://www.scielo.br/scielo.php?script=sci_arttext\&pid=S1517-86922017000200103\&lng=en. http://dx.doi.org/10.1590/1517-869220172302160772 
6. Dázio Eliza Maria Rezende, Zago Márcia Maria Fontão, Fava Silvana Maria Coelho Leite. Uso de álcool e outras drogas entre universitários do sexo masculino e seus significados. Rev. esc. enferm. USP [Internet]. 2016 Oct [cited 2018 Nov 05]; 50 (5): 785-791. Available from: http://www.scielo.br/scielo.php?script=sci_arttext\&pid=S008062342016000500785\&lng=en. http://dx.doi.org/10.1590/s0080-623420160000600011

7. Barbieri Irene, Trivelloni Morena, Zani Bruna, Palacios-Espinosa Ximena. Consumo de sustancias psicoactivas en los contextos recreativos entre estudiantes universitarios en Colombia. Rev. Cienc. Salud [Internet]. 2012 Mar [cited 2018 Nov 05]; 10 ( Suppl (1): 69-86. Available from: http://www.scielo.org.co/scielo.php?script=sci_ arttext\&pid=S1692-72732012000400007\&Ing=en

8. Tomaschewski-Barlem Jamila Geri, Lunardi Valéria Lerch, Ramos Aline Marcelino, Silveira Rosemary Silva da, Barlem Edison Luiz Devos, Ernandes Carolina Mirapalheta. Manifestações da síndrome de burnout entre estudantes de graduação em enfermagem. Texto contexto - enferm. [Internet]. 2013 Sep [cited 2018 Nov 05]; 22 (3): 754762. Available from: http://www.scielo.br/scielo.php?script=sci_arttext\&pid=S0104-07072013000300023\&lng=en. http://dx.doi.org/10.1590/S0104-07072013000300023

9. Massa, L., Silva, T., Sá, I., Barreto, B., Almeida, P. H., \& Pontes, T. (2016). Síndrome de Burnout em professores universitários. Revista de Terapia Ocupacional da Universidade de São Paulo, 27 (2), 180-189. https://doi. org/10.11606/issn.2238-6149.v27i2p180-189

10. Robazzi, Maria Lucia do Carmo Cruz. Relatório Técnico-Científico relacionado ao Processo Chamada Pública: 486327/2013-2, Universal 14/2013 - Faixa C. Financiado pelo Ministério da Ciência e Tecnologia, Conselho Nacional de Desenvolvimento Científico e Tecnológico - CNPq. Disponível em http://efomento.cnpq.br/efomento/ visualizarDocumento.do?metodo=objetoEletronico\&idObjetoEletronico $=133244802$ 